\title{
FORMULASI DAN UJI AKTIVITAS ANTIOKSIDAN LOSIO EKSTRAK METANOL ALGA HIJAU Caulerpa racemosa
}

\author{
Nurlina, M. Ilham Tomagola, Riskawati Angraini \\ Fakultas Farmasi Universitas Muslim Indoneisa, Makassar \\ Email : nurlina.rahman@umi.ac.id
}

\begin{abstract}
Caulerpa racemosa is one type of green algae has the ability to defend against radiation of ultraviolet. Lotion is a liquid or semi-liquid preparation containing one or more active ingredients with a suitable vehicle and provides a comfortable and good feel to the skin. The aim of this research was to obtain the optimum formula based on organoleptic testing, viscosity, $\mathrm{pH}$, flow type, globule of dispersion, and antioxidant activity. The method of this research is experimentally which done by making some design of lotion formulation from methanolic extract of green alga Caulerpa rasemosa. Stability of losio was evaluated include organoleptic testing, $\mathrm{pH}$ measurement, type of emulsion, viscosity, flow type, size and distribution of dispersion globule. Determining of effectiveness of lotion as an antioxidant by IC50 value with UV-Vis spectrophotometry method. Results of this research collected and processed statistically with the Completely Randomized Design method, then made the discussion and taken the conclusion. Based on the evaluation, it was found that Losio containing $0.75 \%$ methanolic extract of Caulerpa racemosa green algae (Formula III) had the most optimum pharmaceutical stability. And the three losio formulas containing methanol extract of Caulerpa racemosa green algae have antioxidant activity.
\end{abstract}

Key words: Green algae, Caulerpa racemosa, lotion of antioxidant.

\section{PENDAHULUAN}

Salah satu jenis alga yang memiliki aktivitas antioksidan adalah jenis dari kelompok Chlorophyceae, dengan habitat iklim tropis seperti di Indonesia memiliki kemampuan pertahanan terhadap radiasi sinar ultraviolet (UV). ${ }^{1}$ Dan Salah satu genus dari kelas Chlorophyceae yang mampu menghasilkan antioksidan adalah genus Caulerpa. Adapun
Komponen bioaktif dari genus Caulerpa dilaporkan berupa senyawa diterpenoid, triterpenoid, komponen nitrogen ${ }^{2}$, mengandung metabolit dari golongan diterpenoid asiklik yaitu trifarin dan senyawa diterpenoid monosiklik yaitu kaulerpol yang dikenal sebagai pro-vitamin A atau retinol ${ }^{3}$, dan komponen polifenol. ${ }^{4}$ Hasil penelitian menyebutkan bahwa komponen polifenol yang terkandung 
dalam Caulerpa racemosa adalah katekol. ${ }^{4}$ Katekol termasuk dalam jenis antioksidan golongan fenol.5,6 Antioksidan golongan fenol merupakan antioksidan yang banyak digunakan karena tidak beracun. ${ }^{5}$

Menurut Supriyono, ekstrak metanol dari alga hijau Caulerpa racemosa memiliki aktivitas antioksidan dan memiliki kandungan total fenol sebesar $42,45 \mathrm{mg} \mathrm{TAE} / \mathrm{g}$ untuk sampel segar dan pada penelitian lainnya oleh Santoso et al., 13,01 mg TAE/g untuk sampel kering. Menurut Matanjun et al, ekstrak metanol alga hijau Culerpa racemosa mampu untuk dapat mengurangi radikal ABTS (2,2'-azino-bis(3ethylbenzothiozoline-6-sulfonic acid) diammonium salt) yang juga dapat mengurangi ion asam besi $\left(\mathrm{Fe}^{3+}\right){ }^{1,7,8}$

Losio adalah sediaan cair atau semicair yang mengandung satu atau lebih bahan aktif dengan pembawa yang cocok. $^{9}$ Losio juga merupakan emulsi tetapi kandungan lilin dan minyaknya lebih rendah dibandingkan krim. Losio memberikan rasa nyaman dan baik pada kulit. ${ }^{10}$

\section{METODE PENELITIAN}

\section{Desain dan Metode Penelitian}

Penelitian ini dilakukan secara eksperimental. Terlebih dahulu dilakukan Optimasi konsentrasi emulgator anionik sabun amin yang akan digunakan dalam formula losio. Setelah mendapatkan formula losio yang stabil, dibuat formulasi losio dengan variasi ekstrak alga hijau Caulerpa racemosa. Kemudian dilakukan evaluasi kestabilan losio meliputi pengamatan organoleptis, pengukuran $\mathrm{pH}$, tipe emulsi, volume kriming, viskositas, tipe aliran, ukuran dan distribusi tetes terdispersi yang selanjutnya dilakukan uji efektivitas sediaan dengan menentukan nilai $\mathrm{IC}_{50}$ dengan metode spektrofotometri UVVIS.

\section{Bahan dan Alat}

Bahan-bahan yang digunakan adalah air suling, asam stearat, DPPH, metanol, metanol p.a, metil paraben, Na. CMC, parafin cair, parfum, propilen glikol, propil paraben, setil alkohol, triethanolamin dan vitamin C. Alat-alat yang digunakan adalah cawan porselin, alat gelas $\left(\right.$ Pyrex $^{\circledR}$ Iwaki TE-32), lemari pendingin (SHARP ${ }^{\circledR)}$, mikroskop $\quad\left(\right.$ Irmeco $\left.^{\circledR}\right)$, penangas air (Idealife $^{\circledR}$ Home Inovation), pipet volume, $\mathrm{pH}$ meter $\left(\mathrm{pH}-201^{\circledR}\right.$ Digital Instruments), rotary vacuum evaporator $\left(\mathrm{IKA}^{\circledR}\right.$ RV 10 basic), spektrofotometer UV-Vis $\left(\right.$ Thermo $\left.^{\circledR}\right)$, termometer, timbangan analitik (OHAUS ${ }^{\circledR}$ Carat series), toples kaca, Ultra-Turrax $\left(\begin{array}{ll}I K A^{\circledR} & \text { T25) dan }\end{array}\right.$ 
viskometer $\quad\left(\right.$ Brookfield $^{\circledR} \quad$ DV-E Viscometer).

\section{Prosedur Kerja}

\section{Penyiapan dan pengolahan sampel}

Alga hijau Caulerpa racemosa diambil di sekitar perairan Ujung Laikang, Takalar. Alga hijau Caulerpa racemosa segar dibersihkan dari kotoran, seperti pasir, batu, cangkang kerang dan rumput laut jenis lainnya. Setelah bersih, alga hijau Caulerpa racemosa dicuci dengan air mengalir sebanyak 5 kali. Selanjutnya, alga segar yang telah dicuci ditimbang sebanyak 1572 gram dan dirajang (dipotong kecil-kecil) kemudian dijemur di bawah sinar matahari hingga kering sekitar 2-3 hari.

\section{Ekstraksi sampel}

Ekstraksi yang dilakukan dengan modifikasi, yakni ekstraksi tunggal dengan menggunakan pelarut metanol sebanyak 4 Liter untuk sampel segar dan 2 Liter untuk sampel kering. Ekstraksi dilakukan secara maserasi (perendaman) selama $3 \times 24$ jam dalam bejana tertutup dan terlindungi dari cahaya matahari langsung.

Selama proses ekstraksi dilakukan pengadukan secara periodik. Setelah diperoleh ekstrak cair, ekstrak cair kemudian dipekatkan dengan menggunakan rotavapor pada suhu $40^{\circ} \mathrm{C}$ selama 5 jam sehingga diperoleh ekstrak pekat. Selanjutnya, ekstrak pekat diuapkan lagi diatas penangas air untuk memperoleh ekstrak kental.

\section{Penyiapan pengujian aktivitas antioksidan}

\section{Pembuatan larutan DPPH 1 mM ${ }^{11}$}

Larutan DPPH $1 \mathrm{mM}$ dibuat dengan cara ditimbang DPPH (2,2difenil-1-pikril hidrazil) sebanyak 0,01985 gram $(19,85 \mathrm{mg})$ dilarutkan dengan $50 \mathrm{~mL}$ methanol p.a dalam labu takar

Pembuatan larutan stok ekstrak metanol alga hijau Caulerpa racemosa ${ }^{11}$

Larutan stok dibuat dengan cara menimbang seksama 0,05 gram (50 mg) ekstrak metanol alga hijau Caulerpa racemosa dalam $25 \mathrm{~mL}$ metanol p.a (2.000 ppm).

\section{Pembuatan seri konsentrasi ekstrak} metanol alga hijau Caulerpa racemosa ${ }^{11}$

Dari larutan stok dengan konsentrasi $2.000 \mathrm{ppm}$ dipipet sebanyak $0,25 \mathrm{~mL}, 0,625 \mathrm{~mL}$ dan 2,5 $\mathrm{mL}$, masing-masing dimasukkan dalam labu tentukur $5 \mathrm{~mL}$ dan dilarutkan dengan metanol p.a sampai dengan $5 \mathrm{~mL}$, sehingga diperoleh konsentrasi dari masing-masing larutan 100 ppm, 250 ppm, dan 1000 ppm. 
Penetuan aktivitas antioksidan ekstrak metanol alga hijau Caulerpa racemosa ${ }^{11}$

Alikot $0,5 \mathrm{~mL}$ ekstrak metanol alga hijau Caulerpa racemosa pada konsentrasi berbeda dicampur dengan $50 \mu \mathrm{l}(0,5 \mathrm{~mL})$ dari $1 \mathrm{mM}$ DPPH (dilarutkan dalam metanol p.a hingga 5 $\mathrm{mL}$ ). Campuran tersebut dihomogenkan menggunakan vortex dan diinkubasi pada suhu ruang selama 1 jam dalam ruang gelap. Absorbansi dibaca pada panjang gelombang $515 \mathrm{~nm}$ menggunakan spektrofotometer UV-VIS. Inhibisi dari penghambatan aktivitas radikal DPPH dalam persen (I\%) dihitung berdasarkan persamaan dari :

$1 \%=[($ Ablanko - Asampel $) /$ Ablanko $] \times 100$ Dimana Ablanko adalah absorbansi dari larutan blanko (mengandung semua pereaksi kecuali sampel uji), Asampel adalah absorbansi dari sampel. Nilai $\mathrm{IC}_{50}$ ditentukan dari grafik yang diplot dari aktivitas peredaman melawan konsentrasi sampel rumput laut hijau Caulerpa racemosa.

\section{Rancangan formula losio}

Optimasi konsentrasi emulgator yang digunakan

Untuk mendapatkan losio yang stabil digunakan jenis emulgator, surfaktan anionik sabun amin, Tea-
Stearat. Untuk surfaktan anionik sabun amin dioptimasi dengan perbandingan 2 : 1 dengan konsentrasi asam stearat mulai $4 \%, 5 \%$ dan $6 \%$, triethanolamin dengan konsentrasi 2-3\%.

\section{Pembuatan losio}

Formulasi losio yang stabil dari hasil optimasi diatas dipilih sebagai dasar formula untuk membuat losio dengan variasi ekstrak Metanol Alga Hijau Caulerpa racemosa.

\section{Pengujian stabilitas fisik}

Stabilitas fisik losio ditentukan dengan mengukur beberapa parameter fisika. Kemudian losio disimpan pada suhu $5^{\circ} \mathrm{C}$ dan $35^{\circ} \mathrm{C}$ secara bergantian masing-masing 12 jam selama 10 siklus untuk mempercepat penguraian. ${ }^{12}$ Setelah itu dilakukan pengukuran kembali beberapa parameter fisika, seperti pemeriksaan organeoleptis, pengukuran $\mathrm{pH}$, pengujian tipe emulsi, pengukuran viskositas.

\section{HASIL PENELITIAN}

Evaluasi penentuan kestabilan dan efektivitas formula losio antioksidan dari ekstrak metanol alga hijau Caulerpa racemosa memberikan hasil penelitian sebagai berikut: 


\section{Pemeriksaan Organoleptis}

Tabel 1. Hasil Pengamatan Organoleptis Sediaan Losio yang Mengandung Ekstrak Metanol Alga Hijau Caulerpa racemosa Sebelum dan Sesudah Kondisi Dipaksakan

\begin{tabular}{|c|c|c|c|c|}
\hline \multirow{2}{*}{ Sediaan } & \multirow{2}{*}{ Formula } & \multirow{2}{*}{ Pemeriksaan } & \multicolumn{2}{|c|}{ Kondisi } \\
\hline & & & Sebelum & Sesudah \\
\hline \multirow{12}{*}{$\begin{array}{l}\text { Losio dengan } \\
\text { Emulgator TEA } \\
\text { dan Asam } \\
\text { Stearat }\end{array}$} & & $\mathrm{Bau}$ & Khas & Khas \\
\hline & 1 & Warna & Hijau muda pucat & Hijau muda pucat \\
\hline & & Konsistensi & Semipadat & Semipadat \\
\hline & & $\mathrm{Bau}$ & Khas & Khas \\
\hline & II & Warna & Hijau muda & Hijau muda \\
\hline & & Konsistensi & Semipadat & Semipadat \\
\hline & & $\mathrm{Bau}$ & Khas & Khas \\
\hline & III & Warna & Hijau Tua & Hijau Tua \\
\hline & & Konsistensi & Semipadat & Semipadat \\
\hline & & $\mathrm{Bau}$ & Khas & Khas \\
\hline & IV & Warna & Putih Gading & Putih Gading \\
\hline & & Konsistensi & Semipadat & Semipadat \\
\hline
\end{tabular}

Keterangan :

Formula : Losio dengan konsentrasi ekstrak 0,25\%

Formula II : : Losio dengan konsentrasi ekstrak 0,5\%

Formula III : : Losio dengan konsentrasi ekstrak 0,75\%

Formula IV : Losio dengan kontrol positif vitamin C 0,1\%

\section{Pengukuran $\mathrm{pH}$ sediaan}

Tabel 2. Hasil Pengukuran pH Sediaan Losio yang Mengandung Ekstrak Metanol Alga Hijau Caulerpa racemosa Sebelum dan Sesudah Kondisi Dipaksakan

\begin{tabular}{ccccc}
\hline Kondisi & Formula I & Formula II & Formula III & Formula IV \\
\hline Sebelum & 7,94 & 7,86 & 7,73 & 6,85 \\
Sesudah & 7,84 & 7,80 & 7,69 & 6,27 \\
\hline
\end{tabular}

Keterangan :

Formula : Losio dengan konsentrasi ekstrak 0,25\%

Formula II : : Losio dengan konsentrasi ekstrak 0,5\%

Formula III : : Losio dengan konsentrasi ekstrak 0,75\%

Formula IV : Losio dengan kontrol positif vitamin C $0,1 \%$

\section{Pengujian Tipe Emulsi Losio}

Tabel 3. Hasil Pengujian Tipe Emulsi Losio yang Mengandung Ekstrak Metanol Alga Hijau Caulerpa racemosa

\begin{tabular}{ccccc}
\hline Kondisi & Formula I & Formula II & Formula III & Formula IV \\
\hline Sebelum & $\mathrm{m} / \mathrm{a}$ & $\mathrm{m} / \mathrm{a}$ & $\mathrm{m} / \mathrm{a}$ & $\mathrm{m} / \mathrm{a}$ \\
Sesudah & $\mathrm{m} / \mathrm{a}$ & $\mathrm{m} / \mathrm{a}$ & $\mathrm{m} / \mathrm{a}$ & $\mathrm{m} / \mathrm{a}$ \\
\hline
\end{tabular}

\section{Keterangan :}

Formula : Losio dengan konsentrasi ekstrak 0,25\%

Formula II : Losio dengan konsentrasi ekstrak 0,5\%

Formula III : Losio dengan konsentrasi ekstrak 0,75\%

Formula IV : Losio dengan kontrol positif vitamin C $0,1 \%$

$\mathrm{m} / \mathrm{a} \quad$ : Tipe emulsi minyak dalam air 


\section{Pengukuran viskositas dan tipe aliran}

Tabel 4. Hasil Pengukuran Viskositas (poise) Sediaan Losio yang mengandung Ekstrak Metanol Alga Hijau Caulerpa racemosa pada $50 \mathrm{Rpm}$ Menggunakan Viskometer Brookfield

\begin{tabular}{|c|c|c|c|c|c|}
\hline \multirow{2}{*}{ Kondisi } & \multirow{2}{*}{ Replikasi } & \multicolumn{4}{|c|}{ Viskositas } \\
\hline & & FI & FII & FIII & FIV \\
\hline \multirow{3}{*}{ Sebelum } & 1 & 56.800 & 58.700 & 47.900 & 83.500 \\
\hline & 2 & 60.000 & 57.100 & 48.700 & 81.000 \\
\hline & 3 & 70.200 & 58.100 & 47.200 & 80.000 \\
\hline \multicolumn{2}{|c|}{ Rata-rata } & 62.333 & 57.967 & 47.933 & 81.500 \\
\hline \multirow{3}{*}{ Sesudah } & 1 & 80.900 & 82.600 & 50.500 & 82.500 \\
\hline & 2 & 98.800 & 90.000 & 56.600 & 87.600 \\
\hline & 3 & 101.300 & 82.900 & 56.300 & 86.500 \\
\hline \multicolumn{2}{|c|}{ Rata-rata } & 93.667 & 85.167 & 54.467 & 85.533 \\
\hline
\end{tabular}

Keterangan :

Formula : Losio dengan konsentrasi ekstrak 0,25\%

Formula II : : Losio dengan konsentrasi ekstrak 0,5\%

Formula III : Losio dengan konsentrasi ekstrak 0,75\%

Formula IV : Losio dengan kontrol positif vitamin C $0,1 \%$

Tabel 5. Hasil Perhitungan Nilai Yield (dyne/cm) ${ }^{2}$ Sediaan Losio Ekstrak Metanol Alga Hijau Caulerpa racemosa

\begin{tabular}{|c|c|c|c|c|c|}
\hline \multirow{2}{*}{ Kondisi } & \multirow{2}{*}{ Replikasi } & \multicolumn{4}{|c|}{ Nilai yield } \\
\hline & & FI & FII & FIII & FIV \\
\hline \multirow{3}{*}{ Sebelum } & 1 & 21.914 & 22.094 & 19.838 & 33.125 \\
\hline & 2 & 28.226 & 26.915 & 20.504 & 31.109 \\
\hline & 3 & 27.187 & 21.876 & 17.522 & 30.898 \\
\hline \multicolumn{2}{|c|}{ Rata-rata } & 25.776 & 23.628 & 19.288 & 31.711 \\
\hline \multirow{3}{*}{ Sesudah } & 1 & 45.749 & 37.519 & 24.476 & 36.056 \\
\hline & 2 & 34.262 & 36.748 & 24.458 & 35.179 \\
\hline & 3 & 42.210 & 37.735 & 22.408 & 33.307 \\
\hline \multicolumn{2}{|c|}{ Rata-rata } & 40.740 & 37.334 & 23.781 & 34.847 \\
\hline
\end{tabular}

Keterangan :

Formula : Losio dengan konsentrasi ekstrak 0,25\%

Formula II : : Losio dengan konsentrasi ekstrak 0,5\%

Formula III : Losio dengan konsentrasi ekstrak 0,75\%

Formula IV : Losio dengan kontrol positif vitamin C 0,1\%

\section{Pengukuran Absorban dan \% inhibisi}

Tabel 6. Hasil Pengukuran Absorbansi dan \% Inhibisi dari Beberapa Konsentrasi Ekstrak Metanol Alga Hijau Caulerpa racemosa

\begin{tabular}{ccc}
\hline Konsentrasi $(\mathbf{p p m})$ & Absorban & \% Inhibisi \\
\hline DPPH & 0,800 & - \\
100 & 0,754 & 5,75 \\
250 & 0,746 & 6,75 \\
1000 & 0,727 & 9,125 \\
\hline
\end{tabular}


Pengukuran aktivitas antioksidan losio yang mengandung ekstrak Metanol Alga Hijau Caulerpa racemosa dan vitamin C sebagai kontrol:

\section{Sebelum kondisi dipaksakan (stress condition)}

Berdasarkan hasil pengukuran awal aktivitas antioksidan diperoleh nilai \% peredaman DPPH $\left(\mathrm{IC}_{50}\right)$ sebagai berikut :

a. FI $(0,25 \%)$ memiliki nilai peredaman $\left(\mathrm{IC}_{50}\right)$ sebesar 91,53\%

b. FII $(0,5 \%)$ memiliki nilai peredaman $\left(\mathrm{IC}_{50}\right)$ sebesar $88,86 \%$

c. FIII $(0,75 \%)$ memiliki nilai peredaman $\left(\mathrm{IC}_{50}\right)$ sebesar 89,51\%

d. Losio Vit. C 0,1\% memiliki nilai peredaman ( $\left.\mathrm{IC}_{50}\right)$ sebesar 81,51\%

Sesudah kondisi dipaksakan (stress condition)

Berdasarkan hasil pengukuran aktivitas antioksidan diperoleh nilai \% peredaman DPPH $\left(\mathrm{IC}_{50}\right)$ sebagai berikut :

a. FI $(0,25 \%)$ memiliki nilai peredaman sebesar $86,70 \%$

b. FII $(0,5 \%)$ memiliki nilai peredaman sebesar $87,63 \%$

c. FIII $(0,75 \%)$ memiliki nilai peredaman $\left(\mathrm{IC}_{50}\right)$ sebesar 87,20\%

d. Losio Vit. C 0,1\% memiliki nilai peredaman $\left(\mathrm{IC}_{50}\right)$ sebesar $84,18 \%$

\section{PEMBAHASAN}

Pertama-tama dilakukan proses ekstraksi pada sampel alga hijau Caulerpa racemosa dalam bentuk segar dan kering. Ekstraksi merupakan salah satu cara pemisahan yang paling banyak digunakan untuk menarik atau memisahkan komponen bioaktif dari alga karena lebih mudah dan sederhana.

Kemudian, dilakukan pemilihan ekstrak metanol alga hijau Caulerpa racemosa antara yang segar atau kering. Berdasarkan hasil ekstraksi yang diperoleh ekstrak segar lebih banyak dibandingkan dengan ekstrak kering, kadar garam dari ekstrak kering lebih banyak dibandingkan ekstrak segar, ekstrak segar lebih mudah larut dalam metanol p.a dibandingkan dengan ekstrak kering. Selain itu berdasarkan penelitian Santoso et al. kandungan total fenol dari ekstrak metanol alga hijau Caulerpa racemosa yang segar lebih tinggi dibandingkan yang kering. Sehingga, pemeriksaan lanjutan dilakukan pada ekstrak metanol alga hijau Caulerpa racemosa yang segar. ${ }^{1}$

Selanjutnya, dilakukan pengujian aktivitas antioksidan dari ekstrak metanol alga hijau Caulerpa racemosa untuk mengetahui nilai $\mathrm{IC}_{50}$ dari ekstrak metanol alga hijau 
Caulerpa racemosa dengan menggunakan metode peredaman DPPH. Dari hasil pengukuran diketahui ekstrak metanol alga hijau Caulerpa racemosa memiliki aktivitas antioksidan akan tetapi berdasarkan hasil penetapan $\mathrm{IC}_{50}$ yang dimiliki sangat lemah (>>0,2 $\mathrm{mg} / \mathrm{ml}$ ), yaitu $1,2466863 \mathrm{mg} / \mathrm{ml}$.

Dibuat empat formula dengan tiga formula dari ekstrak metanol alga hijau Caulerpa racemosa dan satu formula kontrol dari vitamin C $0,1 \%$ dalam basis losio yang sama.

Setelah dibuat tiga formula dengan variasi konsentrasi ekstrak metanol alga hijau Caulerpa racemosa yang berbeda dan satu formula losio vitamin C sebagai kontrol, dilakukan pengujian berdasarkan beberapa parameter fisik diantaranya pemeriksaan organoleptik, pengukuran viskositas, penentuan tipe emulsi, pengukuran $\mathrm{pH}$ dan pengujian aktivitas antioksidannya.

Pengujian kestabilan dilakukan dengan metode kondisi dipaksakan (stress condition) dengan penyimpanan pada suhu $5^{\circ} \mathrm{C}$ dan $35^{\circ} \mathrm{C}$ selama 10 siklus, masing-masing siklus berdurasi 12 jam. Tujuannya adalah untuk mengetahui kestabilan fisik dari krim yang dipengaruhi oleh perbedaan suhu dan waktu penyimpanan dan demikian juga untuk pengukuran aktivitas antioksidan.

Evaluasi kestabilan sediaan losio antioksidan ekstrak metanol alga hijau Caulerpa racemosa yang dilakukan dengan beberapa pengujian antara lain :

\section{Pemeriksaan Organoleptis}

Pemeriksaan organoleptik dilakukan untuk mengetahui ada tidaknya pengaruh penyimpanan pada warna, bau dan konsistensi sediaan. Hasil pengamatan yang diperoleh dari keempat formula sebelum dan sesudah penyimpanan yaitu tidak mengalami perubahan dari segi warna, bau dan konsistensi.

\section{Pengukuran $\mathrm{pH}$}

Pengukuran $\mathrm{pH}$ berkaitan dengan keamanan dalam penggunaan sediaan untuk menghindari terjadinya iritasi pada kulit. Nilai $\mathrm{pH}$ awal dari masing-masing losio sedikit diluar kisaran pH balance yaitu 4,5-6,5 akan tetapi $\mathrm{pH}$ yang dimiliki oleh keempat losio tersebut telah berada sedikit diatas $\mathrm{pH}$ normal sehingga tidak terlalu bersifat basa. Nilai $\mathrm{pH}$ tidak boleh terlalu asam karena dapat menyebabkan iritasi pada kulit sedangkan jika $\mathrm{pH}$ terlalu tinggi dapat menyebabkan kulit bersisik.

$$
\text { Dari hasil penelitian }
$$
menunjukkan semakin tinggi 
konsentrasi ekstrak metanol alga hijau Caulerpa racemosa dalam losio maka $\mathrm{pH}$ sediaan semakin menurun $(\mathrm{pH}$ lebih asam).

\section{Pengujian tipe emulsi}

Pengujian tipe emulsi yaitu dengan menggunakan metode daya hantar listrik. Hasil yang diperoleh dari empat formula baik sebelum dan sesudah kondisi dipaksakan yaitu tipe emulsi m/a (minyak dalam air) yang ditandai dengan bergeraknya jarum voltmeter. Hal ini disebabkan karena jumlah fase air lebih banyak dari pada fase minyak.

\section{Pengukuran tetes terdispersi}

Pengukuran tetes terdipersi dilakukan dengan mengamati ukuran tetes terdispersi pada sediaan dengan menggunakan mikroskop pada perbesaran $40 \times 10$ hingga diperoleh ukuran tetes terdispersi pada tiap sediaan. Namun, karena keterbatasan alat yang tersedia maka tidak dapat diukur diameter pada tiap partikelnya.

\section{Pengukuran viskositas}

Pada penelitian ini viskositas sediaan diukur dengan menggunakan spindel no.64 dengan kecepatan 50 Rpm sebanyak tiga kali replikasi. Penggunaan spindel no.64 disesuaikan dengan kekentalan dari sediaan losio yang diformulasi. Data viskositas yang diperoleh dianalisa secara statistik dengan menggunakan metode rancangan acak kelompok (RAK). Hasil analisis menunjukkan bahwa viskositas dari keempat formula mengalami perubahan yang tidak signifikan pada formula III dan IV pada kondisi sebelum dan sesudah penyimpanan dipercepat. Kemudian dilakukan uji lanjutan menggunakan Beda Nyata Terkecil (BNT) karena nilai koefisien keseragaman tidak lebih dari $20 \%$ yaitu $11,67411 \%$.

Dari hasil analisa terhadap kestabilan sediaan sediaan losio yang mengandung ekstrak metanol alga hijau Caulerpa racemosa sebelum dan sesudah kondisi dipaksakan menunjukkan keempat formula stabil secara farmaseutik. Akan tetapi, yang paling stabil dari keempat formula tersebut adalah terdapat pada formula III dan IV.

Setelah dilakukan analisa terhadap kestabilan sediaan losio dari ekstrak metanol alga hijau Caulerpa racemosa kemudian dilakukan pengujian aktivitas antioksidan dari sediaan losio dengan metode peredaman DPPH sebelum dan sesudah kondisi dipaksakan.

Prinsip kerja metode DPPH adalah berdasarkan adanya senyawa antioksidan yang mendonorkan hidrogen $(H)$ pada DPPH. Reaksi ini 
menyebabkan absorbsi DPPH akan berkurang yang ditandai adanya perubahan warna radikal bebas DPPH yang berwarna ungu menjadi berwarna kuning pucat. Kemudian dengan spektrofotometer UV-VIS diukur serapannya pada panjang gelombang $517 \mathrm{~nm}$.

Dari hasil pengukuran sebelum kondisi dipaksakan didapatkan Formula I memiliki aktivitas antioksidan sebesar $91,53 \%$, formula II sebesar $88,86, \%$, dan untuk formula III sebesar $89,51 \%$. Untuk hasil pengukuran sesudah kondisi dipaksakan terdapat penurunan aktivitas antioksidan sekitar $5 \%$ untuk formula I, $1 \%$ untuk formula II, dan $2 \%$ untuk formula III. Hal ini dapat terjadi, karena adanya pengaruh penyimpanan (suhu) pada saat kondisi dipaksakan. Sebagai kontrol positif digunakan losio vitamin $\mathrm{C}$ dengan konsentrasi 0,1\%.

Berdasarkan hasil diatas dapat disimpulkan bahwa ketiga formula losio yang mengandung ekstrak Metanol Alga Hijau Caulerpa racemosa memenuhi nilai $50 \%$ peredaman DPPH.

\section{KESIMPULAN}

Losio yang mengandung ekstrak metanol alga hijau Caulerpa racemosa pada Formula III memiliki stabilitas farmasetik yang paling optimum. Ketiga formula losio yang mengandung ekstrak metanol alga hijau Caulerpa racemosa memiliki aktivitas antioksidan.

\section{DAFTAR PUSTAKA}

1. Santos J, Aryudhani N, Suseno, Heri S. Kandungan Senyawa Fenol Rumput Laut Hijau Caulerpa racemosa dan Aktivitas Antioksidannya. Bogor : Jurnal Kelautan Nasional, 2009.

2. Amico $V$, Oriente $G$, Piattelli $M$, Tringali C, Fattorusso E, Magno S, Mayol L. Caulerpenyne, An Unusual Sesquiterpenoid From The Green Alga Caulerpa prolifera. Tetrahedron Lett.1978:3593-3596.

3. Fenical W, Paul VJ, Littler MM, Littler DS. Evidence For Chemical Defense In Tropical Green Alga Caulerpa Ashmeadii (Caulerpaceae: Chlorophyta): Isolation of New Bioactive Sesquiterpenoids. Journal Of Chemical Ecology. 1987;13:5.

4. Santoso J. Studies On Nutritional Components And Antioxidant Activity In Several Indonesian Seaweeds (Disertation). Tokyo : University Fisheries, 2002.

5. Ketaren S. Pengantar Teknologi Minyak dan Lemak Pangan. Jakarta : Universitas Indonesia (UI) Press., 1986.

6. Yoshie Y, Wang W, Hsieh YP, Suzuki T. Compositional Difference Of Phenolic Compound Between Two Seaweeds, Halimeda spp. J Tokyo Univ. Fish. 2002;88:21-2 
7. Supriyono, Agus. Aktivitas Beberapa Spesies Rumput Laut dari Pulau Sumba. Jurnal Sains dan Teknologi Indonesia. 2007;9(1):34-38.

8. Matanjun $P$, Mohamed $S$, Mustapha NM, Muhammad K, Ming $\mathrm{CH}$. Antioxidant Activities and Phenolic Content of Eight Species of Seaweeds From North Borneo. J Appl Phycol. 2008;20:367-373.

9. Gennaro, Alfonso. Remington's : The Science And Practice Of Pharmacy. Philadelphia Philadelphia College of Pharmacy and Science, 1990.

10. Rieger MM. Harry 's Cosmeticology $8^{\text {th }}$ Edition. New York : Chemical Publishing,2002.

11. Susanti E, Utomo SB, Syukri Y, Redjeki T. Skrining Fitokimia Dan Analisis Polifenol Aktivitas Antioksidan Ekstrak Metanol Buah Naga Putih (Hylocereus undatus). Jurnal Farmasi Indonesia. 2012;23(1):60-64.

12. Banker. Modern Pharmaceutical. Pennsylvania : Marck Publishing Company. Easton, 1979.

13. Budiman HK. Uji Stabilitas Fisik dan Aktivitas Antioksidan dalam Sediaan Krim Yang Mengandung Ekstrak Kering Tomat (Solanum lycopersicum). (Skripsi). Depok : Universitas Indonesia, 2008. 